\title{
Echocardiographic diagnosis of permanent pacemaker lead malposition in the left ventricle - A case study.
}

\author{
Peter Luke ${ }^{1}$ Ewen Shepherd ${ }^{2}$, Tim Irvine ${ }^{2}$, and Rae Duncan ${ }^{2}$ \\ ${ }^{1}$ Newcastle University Faculty of Medical Sciences \\ ${ }^{2}$ Newcastle Upon Tyne Hospitals NHS Foundation Trust
}

October 5, 2020

\begin{abstract}
Inadvertent endocardial lead malposition is recognised as a rare incident which is usually underreported and if recognised during implantation can be easily corrected. This phenomenon is caused by the ventricular lead unintentionally crossing a pre-existing patent foremen ovale, septal defects (atrial or ventricular) or directly from the aorta via an accidental subclavian puncture resulting in the lead implanting into the left ventricle. While this is a rare occurrence we report the incidental finding of pacemaker lead malposition during a routine follow-up transthoracic echocardiogram and the benefits of three dimensional transoesophageal echocardiography in this patient prior to lead extraction.
\end{abstract}

Case study:

The case study involves a 73 year-old asymptomatic Caucasian male with a previous history of aortic root and bioprosthetic aortic valve replacement (AVR) for a $5.8 \mathrm{~cm}$ ascending aortic aneurysm in 2018 recently attended a routine follow-up transthoracic echocardiography (TTE) at their local hospital. A transvenous dual chamber pacemaker was implanted following the aortic root and AVR for postsurgical transient atrial fibrillation with permanent atrioventricular heart block. The TTE showed a well seated bioprosthetic aortic valve with normal peak and mean gradients and good biventricular function. However, the TTE also clearly demonstrated a ventricular pacing lead originating from the superior aspect of the right atrium, crossing both the atrial septum and mitral valve embedding into the lateral left ventricular (LV) wall (figure one ).

The patient was transferred to a tertiary centre for a transoesophageal echocardiogram (TOE) to assess the risk of lead derived intra-cardiac thrombus and discussion at the multi-disciplinary team meeting for potential lead extraction. A 12-lead electrocardiogram (figure two ) and chest x-ray (figure three ) was performed following admission to the tertiary centre showed underlying atrial fibrillation with a VVI pacemaker induced right bundle branch block morphology. During the TOE three-dimensional imaging was obtained which demonstrated the right ventricular lead crossing the atrial septum through a patent patent foremen ovale and crossing the anterolateral aspect of the mitral valve between $\mathrm{A} 1$ and $\mathrm{P} 1 / 2$ scallops with mild mitral regurgitation. A small sessile mass attached to the lead in the left atrium measuring $11 \times 5 \mathrm{~mm}$ was visualised consistent with thrombus (Figures four - seven ). Infective endocarditis was initially considered as a differential diagnosis especially in the context of an AVR but excluded as the patient did not exhibit any major findings on the Duke criteria such as positive blood cultures or signs of pyrexia. As the patient was high risk for systemic emboli, anticoagulation with warfarin $(5 \mathrm{mg})$ and subcutaneous Tinzaparin (16,000 units) was offered and advised that a repeat TOE was required prior to lead removal in six months.

Discussion:

Suspicion should arise of lead malposition if there is a pacemaker derived right bundle branch block pattern on a 12-lead electrocardiogram instead of the typical left bundle branch block morphology ${ }^{1}$. Utilisation 
of the posterolateral and anterolateral projections can differentiate and provide further evidence that LV malposition may have occurred. Various reports have recommended or used TTE as an imaging modality if there is a suspicion of lead malposition which offers the ability to see the lead using the parasternal, apical and subcostal views ${ }^{2,1}$. A single centre study by Ohlow and colleagues (2016) concluded that $0.34 \%$ of device implants out of 2579 patients between 2007 and 2012 experienced lead malposition of which the leading cause was unusual thoracic anatomy, congenital heart disease and operator inexperience ${ }^{3}$. Patients with LV lead malposition are often asymptomatic until presenting with systemic thromboembolic related complications such as ischemic stroke ${ }^{4}$.

The incidence of cerebral embolic events have been reported as high as $37 \%$ in patients with LV lead malposition $^{3}$. The most common cause of systemic emboli is thrombus or fibrosis formation on the lead or at the site of implantation. At present there is no clear recommendations on management of lead malposition with duration between implant and discovery of lead malposition often influencing treatment. Incidental findings of lead malposition are often managed with anticoagulation and antiplatelet therapy in the first instance with the consideration of percutaneous or surgical lead extraction if deemed appropriate ${ }^{2,1}$. As lifelong anticoagulation with Warfarin with a target international nominal ratio of $2.5-3.5$ has been advised in this population ${ }^{5}$, some papers have not supported the use of anticoagulation in isolation due to reports of patients with lead malposition presenting with an ischemic stroke after prophylactic anticoagulation ${ }^{6,7}$. Other serious complications associated with LV lead malposition include mitral valve leaflet perforation ${ }^{8}$, mitral regurgitation ${ }^{7}$ and endocarditis ${ }^{9}$ which must be taken into consideration when discussing the benefits and risks of lead extraction. While lead repositioning is a potential treatment option, caution must be taken to ensure percutaneous lead extraction does not displace any material which has formed on the lead ${ }^{10}$. One strategy recently reported by Contractor and colleagues (2019) suggested that deploying an embolic protection device in the brachiocephalic and left carotid artery can be used to remove the risk of potential cerebral embolisation ${ }^{11}$. It is beneficial that the patient undergo a TTE and TOE prior to the procedure to identify the presence of mobile thrombus or fibrous material as seen within our case study which may increase the risk of embolisation during extraction ${ }^{12}$. The addition of three dimensional views during a standard TOE views (3DTOE) has been recognised as a useful technique to offer supplementary information of thrombus characteristics and mobility. The advantage of 3DTOE in addition to the already high spatial resolution and superior visualisation of cardiac anatomy seen in standard two-dimensional TOE offers high specificity and sensitivity when visualising presence of intra-cardiac thrombus including left atrial thrombi. A recent case-study recognised that the use of 3DTOE was beneficial when assessing a large LV apical thrombus when magnetic resonance imaging and computed tomography were not appropriate ${ }^{13}$. The ability to use offline reconstructive techniques assists operators to augment image quality while visualising any mobile components and its attachments to the surrounding cardiac structures of a suspected thrombus. Another advantage of using 3DTOE within this particular case-study was the high quality images of mitral valve anatomy which offers a better perspective than $2 \mathrm{D}$ imaging including good visualisation and size of all scallops and mitral valve geometry. The benefits of 3DTOE in this case study was the ability to observe the exact position of the lead crossing the mitral valve with the use of the 'surgeons view', to see if the position of the pacing lead was negatively impeding the behaviour and mobility of the mitral valve leaflets and the thrombus attached to the lead in the left atrium. While some studies have identified that right ventricular lead extraction is viable and safe option of lead extraction, only few publicised cases have demonstrated the safe removal of anomalous rhythm management leads seen in the $\mathrm{LV}^{13,14}$. Recommendations provided by the heart rhythm society in 2009 discussing indications for lead extraction offered caution when considering LV percutaneous lead extraction with the heightened risk of thromboembolic stroke. Although, the review cautioned that surgical removal of anomalous transvenous leads is a class III indication and could be offered at the same time as other surgical interventions requiring cardiopulmonary bypass ${ }^{15}$. Based upon the results of the TEE our patient was offered anticoagulation and antiplatelet therapy in the short-term with the goal of percutaneous lead extraction. A TEE was repeated after six months of medical therapy which showed no evidence of a mass and the patient was consented for percutaneous lead extraction due to the patient's co-morbidities making him high risk for surgery. 


\section{Conflict of interest:}

None.

References:

1). Vanhercke, D., Heytens, W., \& Verloove, H. (2008). Eight years of left ventricle pacing due to inadvertent malposition of a transvenous pacemaker lead in the left ventricle. European Heart Journal Cardiovascular Imaging . Vol 9, Iss 6, pp. 825 - 827. doi.org/10.1093/ejechocard/jen187

2). Wynn, G. J., Weston, C., Cooper, R. J., \& Somauroo, J. D. (2013). Inadvertent left ventricular pacing through a patent foramen ovale: identification, management and implications for postpacemaker implantation checks. BMJ Case Reports . doi: 10.1136/bcr-2012-008312

3). Ohlow, A-M, Roos, M, Lauer, B., von Korn, H., \& Geller, J. C. (2016). Incidence, predictors, and outcome of inadvertent malposition of transvenous pacing or defibrillation lead in the left heart.Europace . Vol 18, pp. 1049 - 1054. doi: 10.1093/europace/euv270.

4). Sivapathasuntharam, D. Hyde, J, A, J., Reay, V., \& Rajkumar, C. (2012). Recurrent strokes caused by a malpositioned pacemaker lead.Age and Aging. Vol 42, Iss 3, pp. 420 - 421. doi.org/10.1093/ageing/afr152

5). Van Gelder, B. M., Bracke, F. A., Oto, A., Yildirir, A., Hass, P. C., Stainback, R. F., Botman, K. J., \& Meijer, A. (2000). Diagnosis and management of inadvertently placed pacing and ICD leads in the left ventricle: a multicenter experience and review of the literature.Pacing and clinical electrophysiology PACE . Vol 23, No 5, pp. $877-883$.

6). Rath, C., Andreas, M., Khazen, C., Wiedemann, D., Habertheuer, A., \& Kocher, A. (2014). Pacemaker lead malpositioning led to subsequent ischemic strokes despite antiplatelet and anticoagulation therapy. Journal of Cardiothoracic surgery . Vol 9, No 54, DOI: 10.1186/1749-8090-9-54.

7). Rodriguez, Y., Baltodano, P., Tower, A., Martinez, C., \& Carrillo, R. (2011). Management of Symptomatic Inadvertently Placed Endocardial Leads in the Left Ventricle. Pacing and clinical electrophysiology PACE . doi.org/10.1111/j.1540-8159.2011.03146.

8). Seki, H., Fukui, T., Shimokawa, T., Manabe, S., Watanabe, Y., Chino, K. \& Takanashi, S. (2009) Malpositioning of a pacemaker lead to the left ventricle accompanied by posterior mitral leaflet injury.Interactive Cardiovascular and Thoracic Surgery . Vol 8, No 2, pp. 235 - 237. DOI: 10.1510/icvts.2008.190793.

9). Schulze, M. R., Ostermaier, R., Franke, Y., Matschke, K., Braun, M, U., \& Strasser, R, H. (2005). Aortic Endocarditis Caused by Inadvertent Left Ventricular Pacemaker Lead Placement. Circulation. Vol 112, pp. e361-e363. doi.org/10.1161/CIRCULATIONAHA.105.541631

10). Almomani, A., Abualsuod, A., Paydak, H., Peer, W. \& Maskouri, W. (2017). Chronic lead malposition diagnosis and management: discussion of two cases and literature review. Clinical Case Reports . Vol 5, No 3, pp. 270 - 276. doi: $10.1002 /$ ccr3.819.

11). Contractor, T., Lawrenz, M., Cooper, J. M., Mandapati, R., \& Abudayyeh, I. (2019). Management of inadvertent lead placement in the left ventricle via a patent foramen ovale: a multidisciplinary approach. Heart Rhythm Case Reports . doi.org/10.1016/j.hrcr.2019.10.020.

12). Trohman, R. G., \& Sharma, P. S. (2018). Detecting and managing device leads inadvertently placed in the left ventricle. Cleveland Clinic Journal of Medicine. Vol 85, No 1, pp. 69 - 75. DOI: https://doi.org/10.3949/ccjm.85a.17012.

13). Fazlinezhad, A., Narayanasamy, H., Wilansky, S., \& Naqvi, T, Z. (2020) Detection of LV apical Thrombus by three dimensional transesophageal echocardiography. Echocardiography. Vol 37, pp. $142-$ 146. https://doi.org/10.1111/echo.14558 
13). Sarubbi, B., Scognamigllo, G., Fusco, F., Melillo, E., D’Alto, M., \& Russo, M.G. (2018). A "longstanding" malpositioned pacing lead. Long-term follow-up after extraction. Monaldi Archives for Chest disease. Vol 88, No 927, DOI: 10.4081/monaldi.2018.927.

14). Burger, H., Ihnken, O., Sperzel, J., Arsalan, M., Walther, T., \& Ziegelhoeffer, T. (2014). Laser-based lead extraction of an accidentally left ventricular placed ICD lead. The Thoracic and Cardiovascular Surgeon . Vol 62, DOI: 10.1055/s-0034-1367441.

15). Wilkoff, B, L., Love, C. J., Byrd, C. L., Bongiorni, M. G., Carrillo, R. G et al. (2009), Transvenous lead extraction: Heart rhythm society expert consensus on facilities, training, indications, and patient management: Heart Rhythm . Vol 6, pp. 1085 - 1104. DOI: 10.1016/j.hrthm.2009.05.020.

\section{Hosted file}

Figure one.pdf available at https://authorea.com/users/364514/articles/484894echocardiographic-diagnosis-of-permanent-pacemaker-lead-malposition-in-the-leftventricle-a-case-study

\section{Hosted file}

Figure two.pdf available at https://authorea.com/users/364514/articles/484894echocardiographic-diagnosis-of-permanent-pacemaker-lead-malposition-in-the-leftventricle-a-case-study

\section{Hosted file}

Figure three.pdf available at https://authorea.com/users/364514/articles/484894echocardiographic-diagnosis-of-permanent-pacemaker-lead-malposition-in-the-leftventricle-a-case-study

\section{Hosted file}

Figure four1.pdf available at https://authorea.com/users/364514/articles/484894echocardiographic-diagnosis-of-permanent-pacemaker-lead-malposition-in-the-leftventricle-a-case-study

\section{Hosted file}

Figure five.pdf available at https://authorea.com/users/364514/articles/484894echocardiographic-diagnosis-of-permanent-pacemaker-lead-malposition-in-the-leftventricle-a-case-study

\section{Hosted file}

Figure six.pdf available at https://authorea.com/users/364514/articles/484894echocardiographic-diagnosis-of-permanent-pacemaker-lead-malposition-in-the-leftventricle-a-case-study

\section{Hosted file}

Figure seven.pdf available at https://authorea.com/users/364514/articles/484894echocardiographic-diagnosis-of-permanent-pacemaker-lead-malposition-in-the-leftventricle-a-case-study 